\title{
Impacts of Digital Technologies for the Provision of Energy Market Services on the Safety of Residents and Consumers
}

\author{
Wadim Strielkowski ${ }^{1,2, *(D)}$, Olga Kovaleva ${ }^{3}$ and Tatiana Efimtseva ${ }^{4,5}$ \\ 1 Department of Agricultural and Resource Economics, University of California, Berkeley, CA 94720, USA \\ 2 Department of Trade and Finance, Faculty of Economics and Management, Czech University of Life Sciences \\ Prague, 16500 Prague, Czech Republic \\ 3 Department of Law, Orenburg State University, 460018 Orenburg, Russia; radaurist@mail.ru \\ 4 Department of Entrepreneurial and Natural-Resources Law, Orenburg Institute (Branch), Kutafin Moscow \\ State Law University, 123993 Moscow, Russia; otvefimtseva@msal.ru \\ 5 Department of Business, Competition and Environmental Law, South Ural State University, \\ 454080 Chelyabinsk, Russia \\ * Correspondence: strielkowski@berkeley.edu or strielkowski@pef.czu.cz
}

check for updates

Citation: Strielkowski, W.; Kovaleva, O.; Efimtseva, T. Impacts of Digital Technologies for the Provision of Energy Market Services on the Safety of Residents and Consumers. Sustainability 2022, 14, 2934 https://doi.org/10.3390/su14052934

Academic Editor: Zubair Baig

Received: 8 February 2022

Accepted: 28 February 2022

Published: 2 March 2022

Publisher's Note: MDPI stays neutral with regard to jurisdictional claims in published maps and institutional affiliations.

Copyright: (C) 2022 by the authors. Licensee MDPI, Basel, Switzerland. This article is an open access article distributed under the terms and conditions of the Creative Commons Attribution (CC BY) license (https:// creativecommons.org/licenses/by/ $4.0 /)$.

\begin{abstract}
Our paper tackles the topic of the digital technologies (represented by the information and communication technologies (ICT)) and the sustainable transformation and energy safety in households represented by the smart homes and the traditional households using smart appliances, gadgets, as well as smart meters connected to the Internet. The rapid growth and adoption of information and communication technologies, such as computers, mobile devices, sensors, and networks, can seriously affect the ways and amounts of energy used by society on its path toward sustainable development. There is a growing interest in characterizing the net energy impact of ICT as well as the Internet of Things (IoT) that arises from indirect effects that offset (or amplify) the energy directly consumed by ICT equipment. However, the society might need some time to build the trust in these new digital technologies and develop the wide social acceptance for their usage. In order to test these assumptions, we employ an empirical econometric model based on the data obtained from the online survey carried out with the randomly selected respondents $(N=523)$ from Russian Federation and the four European Union (EU) countries (Czech Republic, Germany, Poland, and Slovakia). Even with regard to the small size of the sample and thence the limitations stemming from that fact, our results demonstrate that familiarity with smart home technologies and the possibility to alter the tariffs and use flexible energy demand increase the safety of residents and consumers. In addition, it appears that energy efficiency is being rewarded, as energy consumption is sensitive to time constraints on supply. Furthermore, we find that respondents' age (43\% of the respondents belonged to the 36-55 age group), positive attitude to smart home technologies and the possibility to exploit the flexibility of demand offered by the variety of energy tariffs during and off-peaks all yield quite strong and positive relationships and correlations with the willingness to accept the smart home technology and the flexibility of demand. At the same time, concerns over personal security or sharing personal data related to energy consumption do not constitute major concerns for the respondents. Our results have some important impacts on the overall strategy for pursuing sustainable economic development and following the Sustainable Development Goals (SDGs) that might be useful for stakeholders and policymakers as well as for the researchers in this field.
\end{abstract}

Keywords: sustainable development; digitalization; energy safety; smart homes; Internet of Things

\section{Introduction}

Currently, digital technologies find a wide use on the energy market both on the energy supply and demand side. Sustained progress on energy efficiency will keep the growth of aggregate energy demand for data center networks in check over the next years [1-3]. Predictions that digital technologies such as smart meters, smart lighting, and thermostats 
in commercial buildings will considerably reduce energy consumption are based on a limited rebound effect on consumer energy demand $[4,5]$. This reduction would mean total energy savings of $6.5 \mathrm{pWh}$ by 2040, which is twice the total energy consumption of non-OECD countries (countries that do not belong to the Organization for Economic Co-operation and Development (OECD)) [6]. Thence, digital technologies offer enormous potential benefits in terms of energy use. With regard to the above, it is often expected that the digitalization of industries will continue in the near future and that digital technologies will have a far-reaching impact on energy consumption in certain areas of application or in combination [7].

Digital technologies can act as catalysts to help established and new entrants develop new business models, such as through the use of advanced analytics to segment customers and find target groups for new services. They can also be disruptors, opening the door to new entrants such as technology platforms aggregating the production of decentralized (or distributed) energy resources (DERs) so that owners in wholesale power markets can bid on them [8]. Governments should consider exploring a variety of real-world experiments from which to learn. Smart offices, for example, have demonstrated the power of digital technologies to increase the efficiency of lighting, heating, cooling, and water heating by tapping into decentralized sources for flexible load generation and storage. The impact of such systems is substantial: commercial buildings have energy savings and yields equivalent to more than $10 \%$ of annual local energy costs and greenhouse gas emission reductions of up to $40 \%$ thanks to load shifts and improvements in energy efficiency. Digital technologies can also be enablers that enable new performances, such as the reduction of maintenance time and cost by the use of automated drones equipped with cognitive capabilities to inspect facilities on site [9-11].

However, digitization brings new security and data protection risks as it changes markets, businesses and jobs. The digitization of energy adds that huge amounts of data, ubiquitous connectivity, and rapid advancements in artificial intelligence and machine learning enable new applications and business models for global energy systems, from autonomous cars and shared mobility to 3D printing and connected devices. Digital technologies are helping to integrate a higher proportion of variable renewable energy into the grid to better align energy demand with solar and wind power [12].

Many digital technologies such as smart home systems reduce the production of the energy necessary to produce goods and services in all aspects of our lives. For example, in the recent years the International Energy Agency (IEA) has launched an interagency initiative to examine the potential impact of digitalization on energy efficiency and the impact on policy makers. The energy supply sector will benefit from increased productivity and efficiency, as well as improved safety for workers [13].

Thanks to breakthroughs in our national laboratories, industry, and academia, the devices we use in our homes are more energy efficient, save consumers money, and reduce carbon pollution. Thence, let us take a look at some of the technologies that we can expect to see in the next few years on the market that will make our homes more sustainable and smarter. Transformative technologies that improve efficiency can trigger a rebound effect that increases total energy consumption. Much work is being put into modernizing electricity grids, substations, and distribution automation, including the general concept of a smart grid. New electronic devices are connected to the Internet and provide real-time data that facilitates understanding and reduces energy consumption. These technologies are cost-effective and intelligent, and the resulting projects are supported by the office of building technologies of the energy departments.

Our paper considers all of the provisions above and attempts to assess the factors that help the society as a whole and residents and consumers in general to build their trust in the new digital technologies such as smart homes or the Internet of Energy (IoE) and develop the wide social acceptance for their usage. The paper's novel contribution is its mixture of the theoretical analysis and discussion as well as its technical input represented by the empirical model that draws from our own unique data covering several different countries 
represented by the Russian Federation and the four European Union (EU) countries (Czech Republic, Germany, Poland, and Slovakia).

The main objectives of this paper are the comprehensive analysis of the impact of digital technologies for the provision of energy market services on the safety of residents and consumers. We use the case of smart homes for assessing the positive attitudes to the novel information and communication technologies (e.g., Internet of Things (IoT), or the Internet of Energy (IoE)) and the possibility to exploit the flexibility of demand for tackling the ways energy is consumed by the people on the ongoing path toward sustainable development of our society.

The rest of this paper is organized in the following way (see Figure 1): Section 2 provides a concise literature review that outlines the main barriers and factors of the smart home technologies and energy challenges in households. Section 3 discusses the issues and problems of the digitalization and residential emission reduction. Section 4 contemplates over the impacts of digital technologies on energy consumption. Section 5 entitled "Materials and Methods" presents the overview of the data collected via the means of our own questionnaire survey in Russia and four EU countries. Following the presentation of the data, Section 6 presents the results of the empirical model focused on eliciting the links between the smart home technologies and market services. Finally, Section 7 draws the overall conclusions and derives some useful policy implications as well as outlines the pathways for further research.

Introduction:

the outline of the paper's main objectives and novel contribution

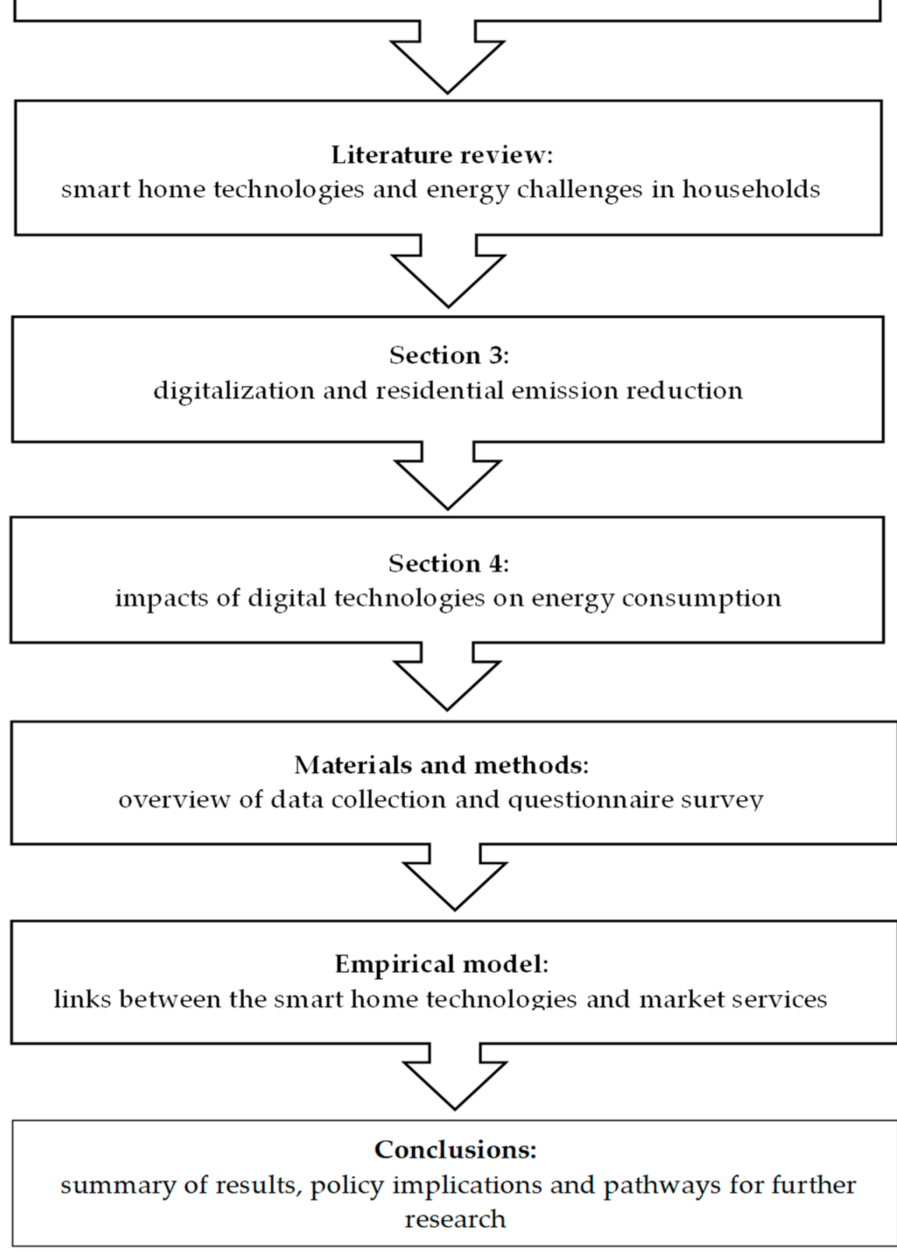

Figure 1. Outline of the generic content of the paper. Source: Own elaboration. 


\section{Literature Review}

Smart home technologies help to solve many energy challenges in modern households. In order to reduce demand during peak periods of high cost, communication and metering technologies notify smart devices in homes and businesses when energy demand is high and track how much electricity is used and when. Since behavior can change the direction of ICT impact, finding ways to better tailor ICT services to consumer needs can help reduce ICT energy costs without significantly affecting customer experience [14].

Smart home technologies can also help people to meet the environmental requirements (for example, to reduce $\mathrm{CO}_{2}$ emissions or to help households to function at a zero-emission mode) $[15,16]$. Another way might be the innovative industrial use of biomass (such as bamboo) as key "green" material — this kind of biomass can be used in order to mitigate and reduce the $\mathrm{CO}_{2}$ emissions [17-19].

The development of smart homes is closely connected with the deployment of the smart grids that offer sustainable solutions covering the entire energy value chain from energy generation through to its transformation to the end consumers [20-22]. They are often seen a viable answer to such issues fostering the decarbonization of the economy, increasing the penetration of renewables into people's daily lives, or moving forward the electrification of transport $[23,24]$.

Smart grids target the electric energy to the household level, connect small distributed devices used to generate and store energy, communicate operating status and demand information, collect information about network prices and conditions, and shift the network from centralized management to collaboration [25-27]. For instance, some relatively simple renewable energy technologies such as the solar photovoltaic (PV) systems can even provide energy services to relatively small electricity consumers, because the investment value of even the smallest solar panels will adapt to their size without sacrificing efficiency [28]. Overall, the use of information and communication technologies can lead to a net reduction in global energy consumption and carbon emissions because digital services optimize or replace traditional non-ICT activities [29,30]. Despite the rapid growth of data services and connected devices, energy demand has been relatively stable in recent years, because the same rapid improvement in efficiency helps reduce the impact of ICT on energy consumption [31]. The technology can also upgrade existing equipment without interrupting service, which is especially important for the large customer base that has installed ICT, thereby providing a way to alleviate reliability and performance issues during the installation, training, and verification phases of product integration methods. Research on specific services, such as those discussed above, can identify specific ICT-supported energy consumption patterns, but rarely involves higher-level impacts other than efficiency and substitution. Figure 2 above outlines the scheme of the smart grid.

The architecture of the system of the smart grid that powers smart homes constitute the generation of energy (either using renewable energy sources, traditional energy sources, and nuclear power), transmission of energy to households (including smart homes with their own battery energy storage and electric vehicles) as well as industry and production sector [32,33].

In this section, we review the literature evaluating the energy consumption impact associated with the implementation of four ICT services (e-commerce, electronic materialization, remote work, monitoring, and control) in construction, transportation, manufacturing, packaging, and waste. 


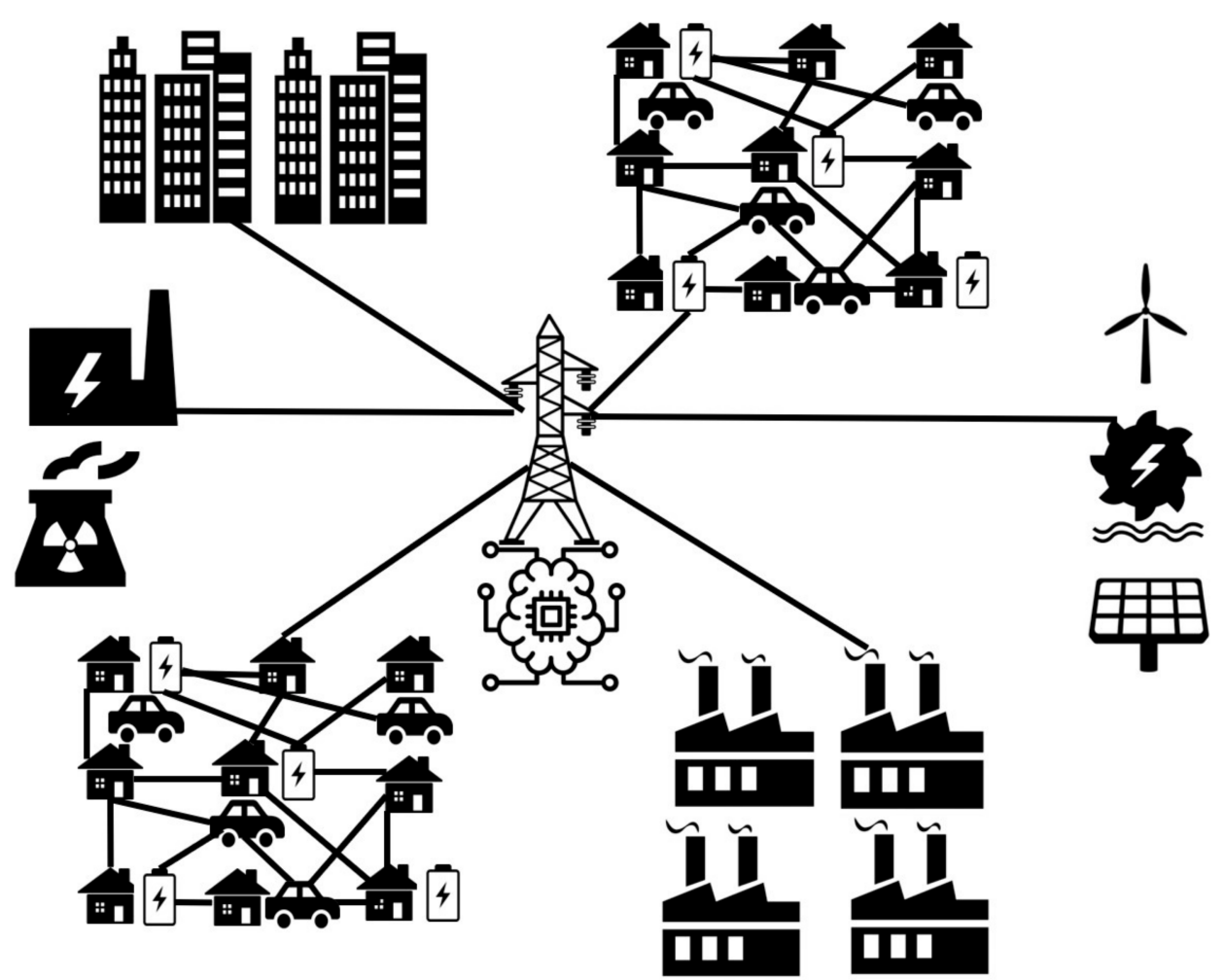

Figure 2. Scheme of the smart grid system. Source: Own elaboration.

In general terms, one way to use ICT to reduce energy consumption and environmental impact is to dematerialize, replacing physical goods and personal activities with equivalent digital services. As the digital services optimize or replace traditional non-ICT activities, such as the use of telecommuting and teleconferencing to reduce business travel, the use of ICT can lead to a net reduction in global energy consumption and environmental impact, especially in smart homes [34,35]. However, even though data services would continue to grow rapidly, the rapid increase in the efficiency of computers, data centers, and data networks appears to have reduced the impact of the technology sector on energy consumption [36,37]. This is what is being researched within the framework of the InovGrid which is an innovative project in Évora, Portugal. It aims to equip the power grid with information and equipment to automate network management, improve service quality, reduce operating costs, improve energy efficiency and environmental sustainability, and improve renewable energy and electric power as well as the penetration rate of electric vehicles [38]. The revolutionary role of ICT has been reflected in the modernization of power grids around the world. ICT is helping to improve network efficiency, profitability, and the integration of the upcoming wave of renewable energy [39]. Many companies in the energy sector, such as utilities, power producers, electrical equipment manufacturers, and transportation companies, need employees with ICT skills because ICTs are increasingly appearing in the development components and systems they use. These service standards are intended to supplement the National Electrical Code and to formulate specific requirements based on experience in order to provide energy customers with safe and reliable services [40].

The provision of energy services such as lighting, thermal comfort, food preparation, communication, and mobility to the people is fundamental to both social and economic good [41,42]. The inclusion of ICTs in energy systems is enabling unprecedented improvements in the monitoring, control, and management of their operation in both developed and developing countries [43,44]. Hence, a typical smart home is the dwelling with its possible functions (security, motion sensors, door control, lights, and lights control) as well as the tools and appliances used for its functioning [45-50]. 
The connection between smart cities and smart homes requires diverse applications in many areas. Many researchers discuss the consulting services provided by intelligent sensors. In contrast, some articles focus on health therapy and supporting features of smart home technologies. Smart home technologies (SHT) include sensors to monitor and interface with devices and mobile devices to enable automation and remote control of households. With regard to this, one has to note that smart home technologies, or "smart", also known as automation or ICT, are being developed for the luxury of living with a modern taste of spice and efficiency. The question is to be asked how smart technologies in the home clarify the role of users in different situations, assess built-in energy efficiency in terms of benefits and costs for different actors and how the boundaries of the home can be extended through connections to the electricity grid and the Internet [51,52]. Sensors and monitoring systems can control environmental variables such as temperature, light movement, and humidity as well as the indoor air quality variables (e.g., $\mathrm{CO}_{2}, \mathrm{VOC}, \mathrm{PM}$, etc. due to the present importance of maintaining well-ventilated spaces that guarantee the health and comfort of the household dwellers. By providing remote monitoring systems with telecommunications technologies, users can control and monitor smart homes and home energy management systems. Control applications such as smartphones, tablets, laptops, and PCs as well as special hardware interfaces and wall-mounted controls support control systems.

Smart home technologies included in the whitepapers include sockets, sockets, window panels, heating, ventilation, and air conditioning (all of these better known as HVAC), water heating, and energy management systems for the home. Distributed clean energy generated by smart homes offers many advantages for a future smart grid. The idea of a smart home special that brings users together to increase energy efficiency does not seem like an ideal place to comment on smart technologies. Information and communication technologies (ICTs) in energy systems can change the meaning for users and the performance of households but not in a way that meets the policy challenges of responding to climate change and providing and maintaining reliable and affordable energy services. The devices in our lives that communicate with each other and receive commands generated by the Internet of Things (IoT) appear to be on track to become more reliable with the widespread adoption of 5G and the low-power wide-area network (LPWAN) technologies that allow to establish and maintain the important connectivity to the devices in cities. Meanwhile, the smart home penetration is expected to reach $25 \%$ by 2026 with over 570 million active users [53].

Currently, the trend is such that we all can see the widespread smart devices in homes worldwide. It is a good test bed for smart technologies and connected services to deploy on a large scale. It is great to be able to control temperature from anywhere in the world, but if one has a normal day at home, tracking one's phone can be a chore whenever a person wants to make a simple adjustment to her or his living room. Anyone's electric car and smart meter are connected to the Internet independently and, for individual reasons, one can start charging her or his car when the electricity is cheaper. Among other things, we have covered some of the most common complaints families have about adapting to smart home technology, such as hating the feeling of being constrained by apps that control their homes. A smart home consists of many separate smart devices, each with its own small challenges. It is not possible for homeowners to buy all of their appliances for their home from the same large appliance manufacturers, so the industry must find ways to use the same technical standards to enable the appliances to talk to each other and integrate into the system. A smart home regards all these things as cooperating, but the challenge is that they work together without many different layers of challenges. As far as the prospects for smart homes and energy are concerned, the relationship between customer and system is increasingly becoming a two-sided concept. This is because the customer is not just someone who is using the system and benefiting from it, but also an economic agent who helps the system to be fully functional. There are some comprehensive networks of smart home systems that offer high-quality comfort, significant energy savings and a high level 
of security. Settings such as temperature control via the homeowner's smartphone can be made to save energy even when not at home.

It also helps to collect data on electricity consumption, energy costs, energy consumption, and planning and installation. Smart homes monitor the efficient use of resources and promote awareness among families of energy savings and environmental sustainability. In the 1990s, Bill Gates took seven years to build his smart home, but for most people, it can be completed in less than a month. On the other hand, the likely decline in the total domestic energy load has encouraged many governments to support the promise of smart home technology. Energy efficiency is a key concern, but smart lighting systems also have environmentally friendly features, such as adapting their brightness to daylight availability and presence in the room. For example, the European standard EN 15232-1 (Energy Performance Building Directive 2010/31/EU) is arranged in line with Directive 2009/72/EC and the Energy Road Map 2050 to promote the integration of smart home technologies to reduce the electricity demand in residential areas. Countries have also put forward many rules of law and subsidy programs to promote the integration of smart homes, such as optimizing heating systems, supporting buildings with energy storage, and deploying smart meters [54].

However, some issues still remain. For example, there is a plethora of challenges that exist in the field of smart homes due to the lack of interoperability, the existence of multiple standards and protocols, the fragmentation of platforms, etc. Quite often, it happens that a smart device from a manufacturer in China would not connect to another device from an established technological company. Nevertheless, there are some interesting alternatives based on open standards (both software and hardware) that offer the possibility to offer solutions capable of integrating multiple platforms (OpenHAB, HomeAssistant, Domoticz, or CasaOS) and that are presented as an alternative to the current situation. There are certain ICT strategies that are being promoted for the coming years such as, for example, the analysis of the economic impact of open-source software and hardware on the European economy by the European Commission's DG CONNECT [55].

Another issue might be the wireless (Wi-Fi or Bluetooth) connection that can be based on different standards and protocols and exclude some appliances or gadgets from the network or to disable them from joining a particular network and making communication with the other devices connected to the same network [56]. All of these issues need to be resolved as soon as possible in the nearest future either by unifying some standards by the producers from different countries and regions or by setting up some universal standards by the policymakers and stakeholders.

\section{Digitalization and Residential Emission Reduction}

In general terms, the ongoing digitalization of the energy market helps to optimize the use of energy and reduce residential emissions. All of these can help to save great amounts of money, especially in the case of poor households who become the victims of the renewable energy deployment and various "green" initiatives. For example, the researchers found that families who remain in poverty often move to larger homes, increasing their energy expenditure. Many of these larger homes are rental properties bought during the Great Recession (the 2007-2009 economic downturn and the global financial crisis) or when the house prices were low in general allowing to acquire more cheap and affordable property [57]. Creating more economic opportunities for low-income residents could lead to a fairer approach to reducing energy consumption through gentrification, she said. The report suggests that city leaders take the age of their housing stock into account before making investments. Lifting people out of poverty and out of old, inefficient homes has helped Minneapolis reduce its greenhouse gas emissions over the past decade. A recent report analyzed the link between emissions from poverty and housing stock in a dozen cities. That helps, according to a recent report of the American Council for an Energy Efficient Economy that examined the relationship between emissions and poverty in housing stock in several cities in the United States [58]. A key element of this effort 
is the introduction of smart home technologies in homes to increase energy efficiency and prevent residents from wasting electricity. With new-build projects, it is relatively easy to design a house intelligently and energy-efficiently, as properties are designed and wired with the necessary technologies in mind. Existing properties, however, can be made more difficult due to property constraints, as uneconomic floor plans, wasteful heating systems, and building materials used can all help reduce a home's energy-saving potential. Smart homes are able to identify the best energy sources at the right time and reduce costs. Consumers can reduce energy consumption and electric heating costs by up to $50 \%$ by using AI-based forecasting without compromising comfort. Advances in solar technology have made it a viable source of energy for a wide range of residential locations. The popular electric vehicle can serve as an energy storage system if required. Another area of energy consumption that often goes unnoticed by smart home technology is the bundling of audio and video $(\mathrm{AV})$ multiroom sources and smart home sources in one place for more effective building management. Smart Home Technology (SHT) refers to devices or systems of devices that provide home residents with networked and improved services to monitor, manage and control home functions related to energy consumption, safety, health and wellness, entertainment, and other aspects of home life that benefit from automation and control. Scripts or explicit programming can guarantee reductions in energy consumption and carbon emissions in the case of smart energy for the home. Without such scripts there is no shutdown for smart home devices if they exceed a certain threshold of emissions and energy consumption.

Popular examples of SHTs include Google Nest or Amazon Alexa, which offer voice activation for music and Internet searches (even though ordering a taxi or buying items from Amazon are also embedded there as possible options). Another thing is Nest thermostats that enable automated heating and programmable heating and ringing security doors that allow video viewing and remote monitoring of the home [59]. Building on the framework of energy insecurity, we examined the literature on energy poverty and household health in order to highlight the disproportionate burden on vulnerable populations to meet their household energy needs.

\section{Impacts of Digital Technologies on Energy Consumption}

In general terms, smart home technology (SHT) refers to devices that provide connected, automated, or advanced services to a certain extent to home residents offering them important feedback of the energy consumption data and information. Home automation systems monitor and control home attributes such as lighting, air conditioning and indoor air quality, entertainment systems, and appliances while making home energy flows and consumption more visible and amenable for the consumers $[60,61]$. The term "smart home" has been used for more than two decades to describe household-controlled energy systems. It sets a certain blueprint of how sustainable and intelligent technologies optimize household energy consumption, reduce waste, and reduce electricity bills [62]. Smartphones and apps give households more insight into the energy consumption of their devices. Controlled energy systems have proved easier for homeowners' lifestyles than normal, nonautomated homes, especially for the elderly and disabled [63,64]. Estimates vary, but industry advocates of connected home and smart home technologies estimate that households could cut their energy bills by $10 \%$ to $25 \%$ [65,66]. However, such claims are speculative, given the lack of robust research. For example, the European standard EN 15232-1 (Energy Efficiency and Buildings Directive 2010/31/EU), in line with Directive 2009/72/EC and Energy Ticket 2050, promotes integration of smart home technologies in order to reduce demand electricity in residential areas [67]. Technology such as electric heat pumps and variable refrigerant flux (VRF) systems are available to meet heating needs and help meet greenhouse gas targets for most climates. Many countries all around the world have also put forward many "rule of law" and subsidy programs to promote smart home integration, such as optimizing heating systems, supporting energy storage in buildings, and deploying smart meters [68-70]. Social research in Australia and the UK shows how 
the IoT increases energy demand [71]. One can identify some well-hidden energy impacts that should be taken into account in IoT research and energy-saving forecasts [72]. For example, the American Council on Energy-Efficient Economies (ACEEE) has published a white paper that discusses the impact of smart home technology on consumer energy use and grid reliability. The paper examines the factors that drive consumers to use smart home technologies and the strategies for competitive, sustainable, and secure energy [73]. The paper provides a good example and a strategy for other countries to follow.

Although many consumers see smart home technology as a recent innovation, it is actually the latest in a long line of breakthroughs in home orientation [74-76]. The invention of dishwashers and microwaves brought enhanced automation to the home, and with the advent of the Internet, a brand new networking infrastructure with networked functionality was introduced. Smart home technology has not only had an obvious effect on increasing the functionality of an average home but has also had a significant impact on the energy industry $[77,78]$. The recent open standards smart home technology alternatives offering solutions for integrating multiple platforms mentioned in Section 2 above might make further changes to this industry in the years to come.

With regard to all of the things mentioned above, it is also interesting to see how the COVID-19 pandemic has shown how valuable it is to engage private customers. As spending on do-it-yourselfers increases, private customers are beginning to recognize the potential of energy management solutions for residential buildings to reduce energy consumption $[79,80]$. Therefore, the consumers should be encouraged to learn about the demand flexibility in their use of electricity and how to benefit from this flexibility. This might be especially relevant for the customers with inertial processes (such as cleaning, washing, or cooking dinners) independent of the time of the day and the peaks in electricity consumption who can easily shift their periods of high consumption to the periods of low electricity cost without disrupting their daily routines and reaching continuous optimization [81-83].

In the coming period, the supply from utilities and third parties will increase the government set standards for accessing customer data that can be used to develop new energy management products at home. Home automation suffers from platform fragmentation and a lack of technical standards, a situation where a variety of home automation devices in terms of hardware variations and differences in the software are running on them making the task of developing applications that work in different and inconsistent technology ecosystems more difficult $[84,85]$. Because of the nature of these devices, there are security, data security, and privacy issues, and patches for bugs in the core operating system may not reach users of older or cheaper devices. Therefore, the marketing departments of home automation companies and other companies with unique technologies must examine methods and strategies to sell their products and services to consumers. Statista Research predicts that by the end of 2018 more than 45 million smart home devices in the United States' households will be installed, making the average sales per household $\$ 490$. The annual growth rate of the home automation industry will be $22 \%$ year-on-year, or $\$ 20$ billion in the United Kingdom alone [86]. This can be attributed to a number of factors, including the continued increases in energy costs, decreasing costs of smart home technologies, current government policies, and incentives for energy consumption and increased awareness among customers of the environmental impact of consuming activities.

The smart home market will grow to become $\$ 1.353$ billion in 2025 , representing a net growth rate of about $12 \%$. Even though the sales of the smart devices are growing fast in China and Southeast Asia at the moment, North America is expected to hold the largest market share by 2025, driven by growing demand for reliable energy management systems for the home, improved security in the home and the growing popularity of smart devices such as tablets and smartphones. The recently available statistics show that $12-16 \%$ of United States households already own a smart device, leaving the entire segment of the global market unaffected by the fact that mass adoption itself is a challenge [87]. 
Therefore, it can be shown that the growth of the smart home industry is driven by a number of factors, including the increasing number of Internet users, the proliferation of smart devices, and the growing disposable income of people in developing countries. For example, some home automation companies are promoting their technological concepts that promise the perfect combination of luxury, relaxation, pleasure, and comfort made possible by intelligent technology. Enjoyment permeates a broad spectrum of ambience and aesthetics through networked technologies such as mood and scene lighting, automated water fountains, intelligent toilets, and audiovisual systems. Other uses include the care for the elderly citizens or the disabled when the smart home technologies monitor the vital statistics of their residents and are capable of helping them to get by in their daily lives. In summary, the smart homes are a trend that is likely to be growing in the years to come and to become ubiquitous.

\section{Materials and Methods}

The empirical model that is presented in the next section of our paper was designed to assess attitude toward smart home technologies and the flexibility of demand. The model uses the data obtained in five different countries represented by the Russian Federation and four European Union countries (Czech Republic, Germany, Poland, and Slovakia).

The data has been collected via the means of the online questionnaire (with the help of the surveying tool SurveyMonkey) carried out with the 523 randomly selected respondents from May 2019 to March 2020. We utilized a network consisting of our own contact points (dubbed "gatekeepers") in the countries in question who supervised teams of graduate students specifically recruited and instructed for the data collection and processing. All ethical norms and standards were ensured, and the written informed consents were obtained from the respondents using the simple online form embedded into our questionnaires. We realize the limitations of this research stemming from the small sample size which was subjected to the data sampling methods used for obtaining our data. Online questionnaires typically high refusal rates and lots of surveys remain unfinished or incomplete. Even with the system of gatekeepers and teams of graduate students in place it proved to be cumbersome to reach at least the size of the sample we managed to reach. However, we still think that the sample of that size can be quite informative and useful for the purposes and goals articulated in this study.

Here, we are reporting the descriptive statistics of our sample. The total number of respondents was 152 in Russia, 86 in the Czech Republic, 133 in Germany, 102 in Poland, and 50 in Slovakia. The average age of our respondents was 42 years. The percentage of males to females in our sample was $54 \%$ to $46 \%$. More than $80 \%$ of respondents had a college degree (32\% had a university degree or higher college degree). The most numerous age group of the respondents was 36-55 years (43\%) which was followed by the age group $25-35$ years (30\%) and 18-24 years (22\%). The least represented age group was the one of $56-80$ years $(5 \%)$. The majority of the respondents $(56 \%)$ had at least primary education and $32 \%$ had university of higher degrees (only $12 \%$ had unfinished primary education).

Table 1 shown above provides an overview of the attitudes and familiarity with the smart homes and smart home appliances expressed by the respondents from our survey split by their respective countries. It becomes apparent that the most positive attitude can be found in Germany followed by Poland, Czech Republic, and Russian Federation. The 29\% negative attitude toward smart home technologies and appliances in Russia can be perhaps explained by the country's totalitarian past marked by the ubiquitous eavesdropping and control by the state authorities which might resemble (at least to more senior citizens who still have the memories of this) smart home surveillance and monitoring systems. The other explanation might be the low familiarity with the concept of smart homes and the fear stemming from not being familiar with this concept and the benefits it might offer. 
Table 1. Respondents' attitudes and familiarity with smart homes and smart home appliances by country.

\begin{tabular}{|c|c|c|c|c|c|}
\hline \multirow[b]{2}{*}{$\begin{array}{c}\text { Smart Homes } \\
\text { Attitudes }\end{array}$} & \multicolumn{5}{|c|}{ Country of Origin } \\
\hline & $\begin{array}{c}\text { Russian } \\
\text { Federation }\end{array}$ & $\begin{array}{c}\text { Czech } \\
\text { Republic }\end{array}$ & Germany & Poland & Slovakia \\
\hline Positive attitude & $44 \%$ & $58 \%$ & $75 \%$ & $62 \%$ & $53 \%$ \\
\hline Negative attitude & $29 \%$ & $12 \%$ & $14 \%$ & $18 \%$ & $14 \%$ \\
\hline Do not know & $27 \%$ & $30 \%$ & $11 \%$ & $20 \%$ & $33 \%$ \\
\hline \multicolumn{6}{|c|}{ Familiarity with the Smart Home Appliances } \\
\hline Smartphone & $95 \%$ & $90 \%$ & $96 \%$ & $95 \%$ & $89 \%$ \\
\hline Smart TV & $32 \%$ & $54 \%$ & $58 \%$ & $55 \%$ & $50 \%$ \\
\hline $\begin{array}{c}\text { Voice assistants } \\
\text { (e.g., Alexa) }\end{array}$ & $25 \%$ & $45 \%$ & $51 \%$ & $48 \%$ & $40 \%$ \\
\hline Smart lights & $13 \%$ & $34 \%$ & $46 \%$ & $41 \%$ & $29 \%$ \\
\hline Motion detectors & $10 \%$ & $30 \%$ & $38 \%$ & $34 \%$ & $23 \%$ \\
\hline Smart cameras & $48 \%$ & $21 \%$ & $26 \%$ & $24 \%$ & $17 \%$ \\
\hline Smart thermostat & $11 \%$ & $13 \%$ & $24 \%$ & $16 \%$ & $12 \%$ \\
\hline Smart window blinds & $4 \%$ & $11 \%$ & $19 \%$ & $17 \%$ & $10 \%$ \\
\hline$N$ & 152 & 86 & 133 & 102 & 50 \\
\hline
\end{tabular}

Source: Own results.

\section{Empirical Model: Smart Home Technologies and Market Services}

In this section, we present the specifications and estimations of our empirical regression model that helps us to assess the attitudes toward smart home technologies and the flexibility of demand among the respondents in five different countries in and outside the EU. The model is based on our previous research on the similar topic (see [88]) or other similar studies that employ the same research approach $[89,90]$.

The model can be specified in the general terms using the following equation (see Equation (1) that follows):

$$
Y_{i j}=\beta_{0 j}+\beta_{1 j} X_{1 i j}+\beta_{2 j} X_{2 i j}+\ldots+\beta_{n j} X_{n i j}+\varepsilon_{i j}
$$

where:

$Y$-a dependent variable that shows the willingness to accept the smart home technology and the flexibility of demand of the respondent $i$ in case of the technology $j$;

$\beta$-an intercept;

$X_{1 i j}, \ldots, X_{n i j}$-dichotomous predictors in the model;

$\varepsilon_{i j}$ - the random error term.

Following the specifications in Equation (1), the level 2 model can be formulated as follows:

$$
\begin{aligned}
& \beta_{0 j}=\gamma_{00}+\gamma_{01} W_{1 j}+\gamma_{02} W_{2 j}+u_{0 j} \\
& \beta_{1 j}=\gamma_{10}+\gamma_{11} W_{1 j}+\gamma_{12} W_{2 j}+u_{1 j}
\end{aligned}
$$

where:

$u_{0 j}, \ldots, u_{1 j}$-random effects;

$W_{1 j}$ and $W_{2 j}$-grand-mean centered and uncentred respectively

We run the model using four consecutive stages by adding additional variables in different stages: starting from the demographic and social characteristics, continuing with the personal characteristics, going to the attitudes to the smart homes, and finally adding the attitudes toward tariffs flexibility and usefulness. Table 2 that is presented below reports the results of the regression model estimation. 
Table 2. Regression model results for the attitude toward smart home technologies and the flexibility of demand.

\begin{tabular}{|c|c|c|c|c|c|c|c|c|}
\hline \multirow[b]{2}{*}{ Variable } & \multicolumn{2}{|c|}{ Stage 1} & \multicolumn{2}{|c|}{ Stage 2} & \multicolumn{2}{|c|}{ Stage 3} & \multicolumn{2}{|c|}{ Stage 4} \\
\hline & $\mathrm{B}(\mathrm{SE})$ & Beta & $\mathrm{B}(\mathrm{SE})$ & $\mathrm{B}(\mathrm{SE})$ & $\mathrm{B}(\mathrm{SE})$ & Beta & $\mathrm{B}(\mathrm{SE})$ & Beta \\
\hline Gender & $\begin{array}{l}-0.054 \\
(0.095)\end{array}$ & -0.034 & $\begin{array}{c}0.041 \\
(0.094)\end{array}$ & 0.032 & $\begin{array}{c}0.043 \\
(0.091)\end{array}$ & 0.028 & $\begin{array}{l}-0.036 \\
(0.085)\end{array}$ & 0.013 \\
\hline Age & $\begin{array}{c}0.009 \\
(0.006)\end{array}$ & $0.223 *$ & $\begin{array}{c}0.011 \\
(0.004)^{* *}\end{array}$ & $0.237^{* *}$ & $\begin{array}{c}0.012 \\
(0.004)^{* *}\end{array}$ & $0.247^{* *}$ & $\begin{array}{c}0.009 \\
(0.004)^{* *}\end{array}$ & $0.121^{* *}$ \\
\hline Income & $\begin{array}{c}0.063 \\
(0.047)\end{array}$ & 0.071 & $\begin{array}{c}0.054 \\
(0.046)\end{array}$ & 0.069 & $\begin{array}{c}0.043 \\
(0.044)\end{array}$ & 0.054 & $\begin{array}{c}0.063 \\
(0.042)\end{array}$ & 0.069 \\
\hline Education & $\begin{array}{l}-0.007 \\
(0.206)\end{array}$ & -0.003 & $\begin{array}{l}-0.035 \\
(0.204)\end{array}$ & -0.021 & $\begin{array}{l}-0.032 \\
(0.101)\end{array}$ & -0.011 & $\begin{array}{c}0.079 \\
(0.101)\end{array}$ & 0.030 \\
\hline Home size & $\begin{array}{c}0.319 \\
(0.098)\end{array}$ & 0.229 & $\begin{array}{c}0.322 \\
(0.095)^{* *}\end{array}$ & $0.223 *$ & $0.268(0.09) *$ & $-0.096^{*}$ & $\begin{array}{c}0.208 \\
(0.086)\end{array}$ & 0.068 \\
\hline Openness to $\mathrm{SH}$ & & & $\begin{array}{c}0.427 \\
(0.089)^{* *}\end{array}$ & 0.287 & $\begin{array}{c}0.229 \\
(0.089)\end{array}$ & 0.077 & $\begin{array}{c}0.101 \\
(0.086)\end{array}$ & 0.066 \\
\hline SH devices & & & $\begin{array}{c}0.057 \\
(0.059)\end{array}$ & 0.054 & $\begin{array}{c}0.046 \\
(0.056)\end{array}$ & 0.043 & $\begin{array}{c}0.031 \\
(0.053)\end{array}$ & 0.021 \\
\hline Trust in $\mathrm{SH}$ & & & $\begin{array}{c}0.076 \\
(0.031)^{* *}\end{array}$ & $0.256^{* *}$ & $\begin{array}{c}0.049 \\
(0.031) *\end{array}$ & $0.096^{*}$ & $\begin{array}{c}0.035 \\
(0.029) \\
\end{array}$ & 0.065 \\
\hline Familiarity with $\mathrm{SH}$ & & & & & $\begin{array}{l}-0.102 \\
(0.093)\end{array}$ & -0.058 & $\begin{array}{l}-0.092 \\
(0.088)\end{array}$ & -0.052 \\
\hline Personal security & & & & & $\begin{array}{c}0.069 \\
(0.043)\end{array}$ & 0.085 & $\begin{array}{c}0.040 \\
(0.041)\end{array}$ & 0.062 \\
\hline Positive attitude to $\mathrm{SH}$ & & & & & $\begin{array}{c}0.544 \\
(0.071)^{* *}\end{array}$ & $0.455^{* *}$ & $\begin{array}{c}0.297 \\
(0.075)^{* *}\end{array}$ & $0.258^{* *}$ \\
\hline Negative attitude to $\mathrm{SH}$ & & & & & $\begin{array}{c}0.024 \\
(0.064)\end{array}$ & 0.023 & $\begin{array}{c}0.036 \\
(0.050)\end{array}$ & 0.032 \\
\hline Tariffs flexibility & & & & & & & $\begin{array}{c}0.520 \\
(0.062)^{* *}\end{array}$ & $0.503^{* *}$ \\
\hline Utilities proofs & & & & & & & $\begin{array}{l}-0.053 \\
(0.043)\end{array}$ & -0.064 \\
\hline Sharing personal data & & & & & & & $\begin{array}{l}-0.022 \\
(0.054)\end{array}$ & -0.025 \\
\hline \multirow[t]{2}{*}{ Constant } & \multicolumn{2}{|c|}{$3.979(0.428)^{* *}$} & \multicolumn{2}{|c|}{$2.092(0.556) *$} & \multicolumn{2}{|c|}{$0.45(0.656)$} & \multicolumn{2}{|c|}{$0.327(0.630)$} \\
\hline & \multicolumn{2}{|c|}{$R^{2}=0.058^{* *}$} & \multicolumn{2}{|c|}{$R^{2}=0.069^{* * *}$} & \multicolumn{2}{|c|}{$R^{2}=0.206^{* * *}$} & \multicolumn{2}{|c|}{$R^{2}=0.205^{* * *}$} \\
\hline
\end{tabular}

Source: Own results. Note: ${ }^{* *}$ Significant at the 0.01 level; ${ }^{* *}$ Significant at the 0.05 level; ${ }^{*}$ Significant at the 0.1 level.

Looking at the results presented in Table 2, it becomes apparent that respondents' age, positive attitude to smart home technologies and the possibility to draw from the flexibility of energy tariffs all yield quite strong and positive relationships and correlations with the willingness to accept the smart home technology and the flexibility of demand. The age variable might also come through as significant due to the fact that older people tend to own their own accommodation (either a house or an apartment) and thence are interested in saving on their energy bills by exploiting the possibilities of using smart meters and mitigating their electricity demand patterns. It also might be due to the fact that older people tend to save more in general because they have to take care of their children and have more family-related expenses. It is apparent that older and more experienced consumers appreciate the possibilities of the smart home technologies and are capable of adjust their consumption of energy based on the smart meters' readings and other inputs. At the same time, it is apparent that the concerns over personal security or sharing personal 
data (e.g., the energy consumption or consumption patterns data over time periods and peaks) is not a major concern for the respondents. The explanation for that finding might be twofold: first of all, currently, most of the people are used to the digital technologies and use them on the daily basis. Mass media run daily reports on how not to become the victim of hackers and how to protect your digital footprint. As a results, lots of people learned their lesson about the digital security and privacy and are not afraid of their personal data theft. Second, this might be due to the fact that ICT went a long way in becoming secure and safe, so the risk of the personal data breaches is minimal.

All in all, the main applications described above are additional services that can be achieved through smart home automation systems. One application is the presence of simulations that execute most of the energy in smart homes. The aim is to reduce energy consumption and household costs as much as possible in order to cover the reduced burden of renewable energy systems on the ground. Taking advantage of local climate and location conditions, planners should incorporate passive strategies for solar heating and cooling as well as energy-efficient landscape management. When building a new house or complementing an existing one, consumers need to learn how to minimize their waste and improve their energy efficiency. Implementing integrated solutions to achieve energy efficiency can reduce power consumption and costs in industrial, commercial and residential environments and reduce energy costs for heating, lighting and appliances by up to one-third. The average family in the United States spends more than $\$ 2000$ on energy bills every year, which means that reducing the energy consumption of one's homes is the most effective way to save money and reduce one's contribution to climate change. The consumers save energy and money, and their homes become more comfortable and durable. Consumers, building owners and tenants will be at the helm of how energy is produced, stored, distributed and consumed with AI-enabled, software-based intelligent energy management solutions.

\section{Conclusions}

Overall, the digital technologies appear to have important and decisive impacts on the provision of energy market services as well as on the safety of residents and energy consumers, in particular those residing in smart homes. With the creation of sustainable smart home networks, buildings will be able to achieve a higher level of energy efficiency and meet their own needs with local renewable energy, decarbonize their heating and cooling systems and allow tenants to charge their electric vehicles in a sustainable and responsible way. In the next decade or so, all kinds of buildings will become energy and carbon negative, which will contribute to the fight against climate change. The use of smart technologies will play a key role in the decarbonization of buildings as they become smarter-by learning how residents use space and services, adapting lighting, air conditioning and other systems to improve use, reduce emissions and energy consumption. The next ten years will be crucial if ambitious global $\mathrm{CO}_{2}$ reduction targets are to be achieved, and decarbonization of buildings is one of the biggest challenges to be addressed. As climate change increases droughts, water-efficient development is becoming increasingly important. Households that utilize energy and water can help low-income households cope with the economic impact of climate change, including volatile energy or water prices and supplies. Moreover, homes that can remain habitable in extreme heat, power outages, and severe storms are critical to protecting their residents. The research on sustainability and energy efficiency is crucial for cities in the age of climate change and global warming trends to improve the quality of life for generations. Community leaders and low-income stakeholders can use the program guidance to understand the benefits of participating in energy-saving initiatives that help communities save energy costs, improve the health and safety of their homes and protect the environment. Our results show that age and familiarity with the smart home technologies also increase people's trust in them including that of sharing their personal energy consumption data. Older residents who are also the owners of their own accommodations, are more aware of the possibilities that smart meters 
and other smart technologies might offer them. Moreover, they are also keen on save on their energy consumption by adjusting their energy demand (which is become more acute nowadays with the rising prices of the natural gas, oil and electricity in Europe and all around the world).

After the COVID-19 pandemic, central and regional governments all around the world are expected to consider improving energy efficiency in buildings and smart homes, taking into account lessons learned and the possibility of reducing energy consumption through commuting and office use. Research into this topic is one of the themes one can encourage in this special topic. New open-source protocols and unified connectivity protocols that are important for smart home and building solutions should also be developed and widely welcomed. Electrical appliances account for a large proportion of the total energy consumption of households due to the large number found in today's households. This is why smart home systems focus on maximizing the energy-efficient operation of large household appliances, in particular household appliances such as washing machines, dishwashers, refrigerators and electric water heaters. In fact, electrical appliances contribute to the energy balance in many ways: washing machines use hot water as electrical energy. With the first type of equipment, their operation must be optimized in such a way that the energy consumption is reduced with regular use. A key element of this effort is the introduction of smart home technology in the home, the purpose of which is to increase energy efficiency and prevent residents from wasting electricity. This can be achieved in a variety of ways, from increasing insulation to designing passive houses, where a property is designed to make optimal use of its surroundings by heating and cooling the room.

As the results stemming from our findings suggest, the energy landscape all around the world changes, our homes need to adapt to reduce our environmental impact. By constructing our current generation of homes with sustainable lines, smart technologies, smart design and a sustainable mix of energy sources, we can save a significant amount of money on energy bills while reducing our carbon footprint. One should always check and evaluate the energy costs of insulation, heat and cooling systems, electrical systems and appliances in order to determine how much energy her or his home consumes and what energy is wasted. It can be inexpensive to improve the insulation and airtightness of her or his home, repair ducts and adjust its system over time, but anew heating or cooling system may be the best option. Research has shown that increased awareness can contribute to a reduction in household electricity consumption, albeit on a small scale. Specialized energy auditors can make concrete proposals to increase the energy efficiency of your homes. If one follows these suggestions, she or he can save 5 to $30 \%$ of one's energy costs. Smart technologies have great potential to reduce the demand for electricity in the housing sector and the associated environmental impacts. In general, larger households have better chances of saving money and reducing environmental impacts through the use of smart technologies. For smart technologies to have a real impact on energy consumption, house management systems need to be reduced. Another important point to be made here in the conclusions of our paper is that the social acceptance of the smart home systems and appliances also should be assured by the private and public sector. Smart technologies need to be promoted and explained to the broader audience for the wide masses of potential users to accept and embrace them in the nearest future.

Speaking about the pathways for further research, it would surely be useful to obtain a larger sample pool of respondents for better results. Moreover, it would also be interesting to extend the sample beyond Czech Republic, Germany, Poland, and Slovakia (which all share some historical past from the times of the Holy Roman Empire or the Habsburg empire and share similar cultural and economic attitudes) to include some other non-EU countries apart from Russia (which is an oil- and gas-abundant economy with low energy prices and hence negligence toward energy saving or demand flexibility in the large share of population).

In addition, a study like this might also benefit not only from the questionnaire surveys and responses of the randomly selected respondents but also from the readings of the smart 
meters installed directly on the appliances or in the households of the energy consumers. This might be a valuable but unfortunately a very expensive study involving smart meter trails that would require teaming up with the energy companies and electricity providers.

Furthermore, it appears to be interesting to extend the empirical analysis based on the model presented in this paper. For example, it might be useful to add country dummies for each respective country in the sample in order to extract the effect of country specific features from the coefficients. However, this would require a larger sample and perhaps a more diverse mix of countries that would be represented by both the renewable-energy proficient Scandinavian countries as well as Mediterranean countries such as Greece, Italy, and Spain.

Author Contributions: Conceptualization, W.S., O.K. and T.E.; methodology, W.S. and O.K.; software, O.K. and T.E.; validation, W.S., O.K. and T.E.; formal analysis, W.S., O.K. and T.E.; investigation, W.S., O.K. and T.E.; resources, W.S., O.K. and T.E.; data curation, W.S., O.K. and T.E.; writing-original draft preparation, W.S., O.K. and T.E.; visualization, W.S.; supervision, W.S.; project administration, W.S.; funding acquisition, O.K. and T.E. All authors have read and agreed to the published version of the manuscript.

Funding: This research received no external funding.

Institutional Review Board Statement: The study was conducted according to the guidelines of the Declaration of Helsinki and approved by the Institutional Review Board (or Ethics Committee) of Czech University of Life Sciences, protocol code DTF2101/2021, 21 January 2021.

Informed Consent Statement: Informed consent was obtained from all subjects involved in the study.

Data Availability Statement: Data available from the authors upon request.

Conflicts of Interest: The authors declare no conflict of interest.

\section{References}

1. Heffron, R.; Körner, M.-F.; Wagner, J.; Weibelzahl, M.; Fridgen, G. Industrial demand-side flexibility: A key element of a just energy transition and industrial development. Appl. Energy 2020, 269, 115026. [CrossRef]

2. Strielkowski, W.; Dvořák, M.; Rovný, P.; Tarkhanova, E.; Baburina, N. 5G Wireless Networks in the Future Renewable Energy Systems. Front. Energy Res. 2021, 9, 714803. [CrossRef]

3. Sarker, E.; Halder, P.; Seyedmahmoudian, M.; Jamei, E.; Horan, B.; Mekhilef, S.; Stojcevski, A. Progress on the demand side management in smart grid and optimization approaches. Int. J. Energy Res. 2021, 45, 36-64. [CrossRef]

4. Sovacool, B.K.; Del Rio, D.D.F. Smart home technologies in Europe: A critical review of concepts, benefits, risks and policies. Renew. Sustain. Energy Rev. 2020, 120, 109663. [CrossRef]

5. Rausser, G.; Strielkowski, W.; Štreimikienè, D. Smart meters and household electricity consumption: A case study in Ireland. Energy Environ. 2018, 29, 131-146. [CrossRef]

6. IEA. Energy Efficiency. Available online: https:/ /www.iea.org/reports/energy-efficiency-2018 (accessed on 28 January 2022).

7. Bañales, S. The enabling impact of digital technologies on distributed energy resources integration. J. Renew. Sustain. Energy 2020, 12, 045301. [CrossRef]

8. Siano, P.; De Marco, G.; Rolan, A.; Loia, V. A Survey and Evaluation of the Potentials of Distributed Ledger Technology for Peer-to-Peer Transactive Energy Exchanges in Local Energy Markets. IEEE Syst. J. 2019, 13, 3454-3466. [CrossRef]

9. Heidarinejad, M.; Dalgo, D.A.; Mattise, N.W.; Srebric, J. Personalized cooling as an energy efficiency technology for city energy footprint reduction. J. Clean. Prod. 2018, 171, 491-505. [CrossRef]

10. Strielkowski, W.; Veinbender, T.; Tvaronavičienė, M.; Lace, N. Economic efficiency and energy security of smart cities. Econ. Res. Ekon. Istraživanja 2020, 33, 788-803. [CrossRef]

11. Kohlhepp, P.; Harb, H.; Wolisz, H.; Waczowicz, S.; Müller, D.; Hagenmeyer, V. Large-scale grid integration of residential thermal energy storages as demand-side flexibility resource: A review of international field studies. Renew. Sustain. Energy Rev. 2019, 101, 527-547. [CrossRef]

12. Moşteanu, N.R. Challenges for organizational structure and design as a result of digitalization and cybersecurity. J. Bus. Retail Manag. Res. 2020, 11, 278-286. [CrossRef]

13. IEA. Digitalization and Energy. 2017. Available online: https://www.iea.org/reports/digitalisation-and-energy (accessed on 29 January 2022).

14. Foroudi, P.; Gupta, S.; Sivarajah, U.; Broderick, A. Investigating the effects of smart technology on customer dynamics and customer experience. Comput. Hum. Behav. 2018, 80, 271-282. [CrossRef] 
15. Herrero, S.T.; Nicholls, L.; Strengers, Y. Smart home technologies in everyday life: Do they address key energy challenges in households? Curr. Opin. Environ. Sustain. 2018, 31, 65-70. [CrossRef]

16. Khan, N.; Baloch, M.A.; Saud, S.; Fatima, T. The effect of ICT on $\mathrm{CO}_{2}$ emissions in emerging economies: Does the level of income matters? Environ. Sci. Pollut. Res. 2018, 25, 22850-22860. [CrossRef]

17. Borowski, P.F.; Patuk, I.; Bandala, E.R. Innovative Industrial Use of Bamboo as Key "Green” Material. Sustainability 2022, 14, 1955. [CrossRef]

18. Manandhar, R.; Kim, J.-H.; Kim, J.-T. Environmental, social and economic sustainability of bamboo and bamboo-based construction materials in buildings. J. Asian Arch. Build. Eng. 2019, 18, 49-59. [CrossRef]

19. Chaowana, K.; Wisadsatorn, S.; Chaowana, P. Bamboo as a Sustainable Building Material—Culm Characteristics and Properties. Sustainability 2021, 13, 7376. [CrossRef]

20. Strielkowski, W. Social and Economic Implications for the Smart Grids of the Future. Econ. Sociol. 2017, 10, 310-318. [CrossRef]

21. Prieto González, L.; Fensel, A.; Gómez Berbís, J.M.; Popa, A.; de Amescua Seco, A. A Survey on Energy Efficiency in Smart Homes and Smart Grids. Energies 2021, 14, 7273. [CrossRef]

22. Inderwildi, O.; Zhang, C.; Wang, X.; Kraft, M. The impact of intelligent cyber-physical systems on the decarbonization of energy. Energy Environ. Sci. 2020, 13, 744-771. [CrossRef]

23. Monteiro, V.; Afonso, J.A.; Ferreira, J.C.; Afonso, J.L. Vehicle Electrification: New Challenges and Opportunities for Smart Grids. Energies 2019, 12, 118. [CrossRef]

24. Strielkowski, W. Social Impacts of Smart Grids: The Future of Smart Grids and Energy Market Design, 1st ed.; Elsevier: London, UK, 2019.

25. Kakran, S.; Chanana, S. Smart operations of smart grids integrated with distributed generation: A review. Renew. Sustain. Energy Rev. 2018, 81, 524-535. [CrossRef]

26. Ghorbanian, M.; Dolatabadi, S.H.; Masjedi, M.; Siano, P. Communication in Smart Grids: A Comprehensive Review on the Existing and Future Communication and Information Infrastructures. IEEE Syst. J. 2019, 13, 4001-4014. [CrossRef]

27. Kim, S.C.; Ray, P.; Reddy, S.S. Features of Smart Grid Technologies: An Overview. ECTI Trans. Electr. Eng. Electron. Commun. 2019, 17, 169-180. [CrossRef]

28. Vaka, M.; Walvekar, R.; Rasheed, A.K.; Khalid, M. A review on Malaysia's solar energy pathway towards carbon-neutral Malaysia beyond COVID'19 pandemic. J. Clean. Prod. 2020, 273, 122834. [CrossRef] [PubMed]

29. Zhou, X.; Zhou, D.; Wang, Q.; Su, B. How information and communication technology drives carbon emissions: A sector-level analysis for China. Energy Econ. 2019, 81, 380-392. [CrossRef]

30. Williams, L.; Sovacool, B.K.; Foxon, T.J. The energy use implications of 5G: Reviewing whole network operational energy, embodied energy, and indirect effects. Renew. Sustain. Energy Rev. 2022, 157, 112033. [CrossRef]

31. Strielkowski, W.; Streimikiene, D.; Fomina, A.; Semenova, E. Internet of Energy (IoE) and High-Renewables Electricity System Market Design. Energies 2019, 12, 4790. [CrossRef]

32. Powroźnik, P.; Szcześniak, P.; Piotrowski, K. Elastic Energy Management Algorithm Using IoT Technology for Devices with Smart Appliance Functionality for Applications in Smart-Grid. Energies 2022, 15, 109. [CrossRef]

33. Li, W.; Logenthiran, T.; Phan, V.-T.; Woo, W.L. A Novel Smart Energy Theft System (SETS) for IoT-Based Smart Home. IEEE Internet Things J. 2019, 6, 5531-5539. [CrossRef]

34. Park, C.; Heo, W. Review of the changing electricity industry value chain in the ICT convergence era. J. Clean. Prod. 2020, 258, 120743. [CrossRef]

35. Lange, S.; Pohl, J.; Santarius, T. Digitalization and energy consumption. Does ICT reduce energy demand? Ecol. Econ. 2020, 176, 106760. [CrossRef]

36. Masanet, E.; Shehabi, A.; Lei, N.; Smith, S.; Koomey, J. Recalibrating global data center energy-use estimates. Science 2020, 367, 984-986. [CrossRef] [PubMed]

37. Malmodin, J.; Lundén, D. The Energy and Carbon Footprint of the Global ICT and E\&M Sectors 2010-2015. Sustainability 2018, 10, 3027. [CrossRef]

38. E-redes, Projeto InovGrid. Available online: https://www.e-redes.pt/en/power-grids-future/intelligent-networks/project (accessed on 4 February 2022).

39. Abubakr, M.; Abbas, A.T.; Tomaz, I.; Soliman, M.S.; Luqman, M.; Hegab, H. Sustainable and Smart Manufacturing: An Integrated Approach. Sustainability 2020, 12, 2280. [CrossRef]

40. U.S. Department of Energy. Electricity Industry Primer. Available online: https://www.energy.gov/sites/prod/files/2015/12/f2 8/united-states-electricity-industry-primer.pdf (accessed on 4 February 2022).

41. Millward-Hopkins, J.; Steinberger, J.K.; Rao, N.D.; Oswald, Y. Providing decent living with minimum energy: A global scenario. Glob. Environ. Chang. 2020, 65, 102168. [CrossRef]

42. Castán Broto, V.; Kirshner, J. Energy access is needed to maintain health during pandemics. Nat. Energy 2020, 5, 419-421. [CrossRef]

43. Ahmad, T.; Zhang, D. Using the internet of things in smart energy systems and networks. Sustain. Cities Soc. $2021,68,102783$. [CrossRef] 
44. Sabory, N.R.; Senjyu, T.; Danish, M.S.S.; Ahmadi, M.; Zaheb, H.; Halim, M. A Framework for Integration of Smart and Sustainable Energy Systems in Urban Planning Processes of Low-Income Developing Countries: Afghanistan Case. Sustainability 2021, 13, 8428. [CrossRef]

45. Asaithambi, S.P.R.; Venkatraman, S.; Venkatraman, R. Big Data and Personalisation for Non-Intrusive Smart Home Automation. Big Data Cogn. Comput. 2021, 5, 6. [CrossRef]

46. Stolojescu-Crisan, C.; Crisan, C.; Butunoi, B.-P. An IoT-Based Smart Home Automation System. Sensors 2021, 21, 3784. [CrossRef]

47. Aliero, M.S.; Qureshi, K.N.; Pasha, M.F.; Jeon, G. Smart Home Energy Management Systems in Internet of Things networks for green cities demands and services. Environ. Technol. Innov. 2021, 22, 101443. [CrossRef]

48. Wang, J.; Spicher, N.; Warnecke, J.M.; Haghi, M.; Schwartze, J.; Deserno, T.M. Unobtrusive Health Monitoring in Private Spaces: The Smart Home. Sensors 2021, 21, 864. [CrossRef] [PubMed]

49. Isnen, M.; Kurniawan, S.; Garcia-Palacios, E. A-SEM: An adaptive smart energy management testbed for shiftable loads optimisation in the smart home. Measurement 2020, 152, 107285. [CrossRef]

50. Gram-Hanssen, K.; Darby, S.J. "Home is where the smart is?" Evaluating smart home research and approaches against the concept of home. Energy Res. Soc. Sci. 2018, 37, 94-101. [CrossRef]

51. Bibri, S.E.; Krogstie, J. Environmentally data-driven smart sustainable cities: Applied innovative solutions for energy efficiency, pollution reduction, and urban metabolism. Energy Inform. 2020, 3, 1-59. [CrossRef]

52. Jain, M.; Siva, V.; Hoppe, T.; Bressers, H. Assessing governance of low energy green building innovation in the building sector: Insights from Singapore and Delhi. Energy Policy 2020, 145, 111752. [CrossRef]

53. Statista. Smart Home. 2022. Available online: https://www.statista.com/outlook/dmo/smart-home/worldwide (accessed on 15 February 2022).

54. Lobaccaro, G.; Carlucci, S.; Löfström, E. A Review of Systems and Technologies for Smart Homes and Smart Grids. Energies 2016 9, 348. [CrossRef]

55. Blind, K.; Böhm, M.; Grzegorzewska, P.; Katz, A.; Muto, S.; Pätsch, S.; Schubert, T. The Impact of Open Source Software and Hardware on Technological Independence, Competitiveness and Innovation in the EU Economy; Final Study Report; European Union: Brussels, Belgium, 2021; Available online: https:/ /www.ospi.es/export/sites/ospi/documents/documentos/CNECT_OpenSourceStudy_ EN_28_6_2021_LMBhSihnCeC7JEDsHXkK1J1Z0_79021_compressed.pdf (accessed on 17 February 2022).

56. Reyes-Campos, J.; Alor-Hernández, G.; Machorro-Cano, I.; Olmedo-Aguirre, J.O.; Sánchez-Cervantes, J.L.; Rodríguez-Mazahua, L. Discovery of Resident Behavior Patterns Using Machine Learning Techniques and IoT Paradigm. Mathematics 2021, 9, 219. [CrossRef]

57. Iacoviello, M.; Pavan, M. Housing and debt over the life cycle and over the business cycle. J. Monet. Econ. 2021, 60, 221-238. [CrossRef]

58. Goldstein, B.; Gounaridis, D.; Newell, J.P. The carbon footprint of household energy use in the United States. Proc. Natl. Acad. Sci. USA 2020, 117, 19122-19130. [CrossRef] [PubMed]

59. Perez, A.J.; Zeadally, S.; Cochran, J. A review and an empirical analysis of privacy policy and notices for consumer Internet of things. Secur. Priv. 2018, 1, e15. [CrossRef]

60. Sun, Q.; Yu, W.; Kochurov, N.; Hao, Q.; Hu, F. A Multi-Agent-Based Intelligent Sensor and Actuator Network Design for Smart House and Home Automation. J. Sens. Actuator Netw. 2013, 2, 557-588. [CrossRef]

61. Darby, S. The Effectiveness of Feedback on Energy Consumption. A Review for DEFRA of the Literature on Metering, Billing and Direct Displays; Environmental Change Institute; University of Oxford: Oxford, UK, 2006; Available online: https://www.eci.ox.ac.uk/ research/energy / downloads/smart-metering-report.pdf (accessed on 17 February 2022).

62. Machorro-Cano, I.; Alor-Hernández, G.; Paredes-Valverde, M.A.; Rodríguez-Mazahua, L.; Sánchez-Cervantes, J.L.; OlmedoAguirre, J.O. HEMS-IoT: A Big Data and Machine Learning-Based Smart Home System for Energy Saving. Energies 2020, $13,1097$. [CrossRef]

63. O'brolcháin, F.; Gordijn, B. Privacy challenges in smart homes for people with dementia and people with intellectual disabilities Ethic Inf. Technol. 2019, 21, 253-265. [CrossRef]

64. Pal, D.; Funilkul, S.; Charoenkitkarn, N.; Kanthamanon, P. Internet-of-Things and Smart Homes for Elderly Healthcare: An End User Perspective. IEEE Access 2018, 6, 10483-10496. [CrossRef]

65. Nicholls, L.; Strengers, Y. Robotic vacuum cleaners save energy? Raising cleanliness conventions and energy demand in Australian households with smart home technologies. Energy Res. Soc. Sci. 2019, 50, 73-81. [CrossRef]

66. Nelson, S.; Allwood, J.M. Technology or behaviour? Balanced disruption in the race to net zero emissions. Energy Res. Soc. Sci. 2021, 78, 102124. [CrossRef]

67. European Commission. National Energy Efficiency Plan 2020. Available online: https://ec.europa.eu/energy/sites/default/ files/si_neeap_2017_en.pdf (accessed on 20 January 2022).

68. McIlwaine, N.; Foley, A.M.; Morrow, D.J.; Al Kez, D.; Zhang, C.; Lu, X.; Best, R.J. A state-of-the-art techno-economic review of distributed and embedded energy storage for energy systems. Energy 2021, 229, 120461. [CrossRef]

69. El-Azab, R. Smart homes: Potentials and challenges. Clean Energy 2021, 5, 302-315. [CrossRef]

70. Kim, H.; Choi, H.; Kang, H.; An, J.; Yeom, S.; Hong, T. A systematic review of the smart energy conservation system: From smart homes to sustainable smart cities. Renew. Sustain. Energy Rev. 2021, 140, 110755. [CrossRef] 
71. Strengers, Y.; Nicholls, L. Convenience and energy consumption in the smart home of the future: Industry visions from Australia and beyond. Energy Res. Soc. Sci. 2017, 32, 86-93. [CrossRef]

72. Neshenko, N.; Bou-Harb, E.; Crichigno, J.; Kaddoum, G.; Ghani, N. Demystifying IoT Security: An Exhaustive Survey on IoT Vulnerabilities and a First Empirical Look on Internet-Scale IoT Exploitations. IEEE Commun. Surv. Tutor. 2019, 21, $2702-2733$. [CrossRef]

73. ACEEE. Energy Impacts of Smart Home Technologies. Available online: https://www.aceee.org/research-report/a1801 (accessed on 21 January 2022).

74. Aldossari, M.Q.; Sidorova, A. Consumer Acceptance of Internet of Things (IoT): Smart Home Context. J. Comput. Inf. Syst. 2020, 60, 507-517. [CrossRef]

75. Marikyan, D.; Papagiannidis, S.; Alamanos, E. A systematic review of the smart home literature: A user perspective. Technol. Forecast. Soc. Chang. 2019, 138, 139-154. [CrossRef]

76. Cheng, P.; Mugge, R.; De Bont, C. "Smart home system is like a mother": The potential and risks of product metaphors to influence consumers' comprehension of really new products (RNPs). Int. J. Des. 2019, 13, 1-19. [CrossRef]

77. Murshed, M. An empirical analysis of the non-linear impacts of ICT-trade openness on renewable energy transition, energy efficiency, clean cooking fuel access and environmental sustainability in South Asia. Environ. Sci. Pollut. Res. 2020, 27, 36254-36281. [CrossRef]

78. Santiago, I.; Moreno-Munoz, A.; Quintero-Jiménez, P.; Garcia-Torres, F.; Gonzalez-Redondo, M.J. Electricity demand during pandemic times: The case of the COVID-19 in Spain. Energy Policy 2021, 148, 111964. [CrossRef]

79. Strielkowski, W.; Firsova, I.; Lukashenko, I.; Raudeliūnienė, J.; Tvaronavičienè, M. Effective Management of Energy Consumption during the COVID-19 Pandemic: The Role of ICT Solutions. Energies 2021, 14, 893. [CrossRef]

80. Chen, C.-F.; Nelson, H.; Xu, X.; Bonilla, G.; Jones, N. Beyond technology adoption: Examining home energy management systems, energy burdens and climate change perceptions during COVID-19 pandemic. Renew. Sustain. Energy Rev. 2021, 145, 111066. [CrossRef]

81. Borowski, P.F. Innovative Processes in Managing an Enterprise from the Energy and Food Sector in the Era of Industry 4.0 Processes 2021, 9, 381. [CrossRef]

82. Honarmand, M.E.; Hosseinnezhad, V.; Hayes, B.; Shafie-Khah, M.; Siano, P. An Overview of Demand Response: From its Origins to the Smart Energy Community. IEEE Access 2021, 9, 96851-96876. [CrossRef]

83. Rezaei, M.; Dampage, U.; Das, B.K.; Nasif, O.; Borowski, P.F.; Mohamed, M.A. Investigating the Impact of Economic Uncertainty on Optimal Sizing of Grid-Independent Hybrid Renewable Energy Systems. Processes 2021, 9, 1468. [CrossRef]

84. Pawlak, J.; Imani, A.F.; Sivakumar, A. How do household activities drive electricity demand? Applying activity-based modelling in the context of the United Kingdom. Energy Res. Soc. Sci. 2021, 82, 102318. [CrossRef]

85. Borowski, P.F. New Technologies and Innovative Solutions in the Development Strategies of Energy Enterprises. HighTech Innov. J. 2020, 1, 39-58. [CrossRef]

86. Caccavale, M. The Impact of The Digital Revolution on The Smart Home Industry. Available online: https://www.forbes.com/ sites / forbesagencycouncil/2018/09/24/the-impact-of-the-digital-revolution-on-the-smart-home-industry/?sh=6625d9f73c76 (accessed on 1 February 2022).

87. Zdnet. 80 Million US Households Intend to Purchase a New Type of Smart Home Device. 2020. Available online: https:/ / www.zdnet.com/article/80-million-us-households-intend-to-purchase-a-new-type-of-smart-home-device (accessed on 26 January 2022).

88. Korneeva, E.; Olinder, N.; Strielkowski, W. Consumer Attitudes to the Smart Home Technologies and the Internet of Things (IoT) Energies 2021, 14, 7913. [CrossRef]

89. Shouran, Z.; Ashari, A.; Priyambodo, T. Internet of Things (IoT) of Smart Home: Privacy and Security. Int. J. Comput. Appl. 2019, 182, 3-8. [CrossRef]

90. Yang, H.; Lee, H.; Zo, H. User acceptance of smart home services: An extension of the theory of planned behavior. Ind. Manag. Data Syst. 2017, 117, 68-89. [CrossRef] 